\title{
TCD Diastolic Velocity Decay and Pulsatility Index Increment in PVS Cases
}

\author{
Jesús Perez-Nellar, Calixto Machado, Claudio E. Scherle, Mauricio Chinchilla
}

\begin{abstract}
Background: Functional neuroimaging has provided new insights for assessing cerebral function in persistent vegetative state patients (PVS). Compared to controls, positron emission tomography and single photon emission tomography have shown a substantial reduction of global brain cerebral glucose metabolism and perfusion in PVS. Doppler ultrasonography (TCD) assesses local blood flow velocity and direction in the proximal portions of large intracranial arteries; it is a noninvasive technique, and it can be carried out at the bedside. To date, few studies have applied TCD to study PVS. Methods: We assessed intracranial circulation by TCD in five PVS patients. The cause of brain insult was hypoxic encephalopathy in four cases, and the other suffered an embolic cerebral infarct causing a top of the basilar artery syndrome. The sample volume was set at $12 \mathrm{~mm}$; power output and gain settings were maximized as needed. The temporal bone acoustic window was not suitable for intracranial vessel insonation in all patients. As an alternative, the internal carotid artery siphon was assessed by orbital insonation between $55-70 \mathrm{~mm}$. Results: Systolic velocity was within a normal range, between 44 and $62 \mathrm{~cm} / \mathrm{second}$ in all cases. However, the diastolic amplitude was reduced, as well as the end diastolic velocity, and the pulsatility index was increased in all patients. Conclusions: We conclude that TCD diastolic velocity decrement and PI augmentation in our cases might be related to uncoupling of cerebral blood flow and cerebral metabolic rate, arising from reduced cerebral glucose consumption and oxygen uptake, after extensive brain injury.
\end{abstract}

RÉSUMÉ: Déclin de la vélocité diastolique à l'échographie Doppler et accroissement de l'index de pulsatilité chez les patients en état végétatif persistant. Contexte : La neuroimagerie fonctionnelle a fourni de nouvelles avenues pour l'évaluation de la fonction cérébrale chez les patients en état végétatif persistant (EVP). La tomographie par émission de positons et la tomographie par émission d'un seul photon ont démontré une diminution substantielle du métabolisme et de la perfusion cérébrale du glucose dans tout le cerveau chez les patients en EVP par rapport aux sujets témoins. L'échographie Doppler (ED) évalue la vélocité du flux sanguin local et sa direction dans les portions proximales des grosses artères intracrâniennes. C'est une technique non effractive et elle peut être effectuée au chevet du patient. Cependant peu d'études ont utilisé l'ED pour étudier l'EVP. Méthodologie : Nous avons évalué la circulation intracrânienne par ED chez 5 patients en EVP. Une encéphalopathie hypoxique était la cause du dommage cérébral chez 4 patients et l'autre avait subi un infarctus cérébral par embolie à la bifurcation du tronc cérébral (top of the basilar artery syndrome). Le volume de l'échantillon était fixé à $12 \mathrm{~mm}$ et le réglage de la puissance de sortie et du gain étaient maximisés au besoin. La fenêtre acoustique de l'os temporal n'était pas propice à l'échographie des vaisseaux intracrâniens chez tous nos patients. Le siphon de la carotide interne a été évalué par échographie orbitaire entre 55-70 mm chez ces patients. Résultats : La vélocité systolique était dans l'écart normal, entre 44 et $62 \mathrm{~cm}$ par seconde, chez tous les patients. Cependant, l'amplitude diastolique était réduite de même que la vélocité en fin de diastole et l'indice de pulsatilité (IP) était diminué chez tous les patients. Conclusions : Nous concluons que la diminution de la vélocité diastolique à l'ED et l'augmentation de l'IP chez nos patients pourraient être reliées à un découplage du flux sanguin cérébral et du taux de métabolisme cérébral suite à une consommation réduite de glucose et d'oxygène au niveau du cerveau après un dommage cérébral important.

Can. J. Neurol. Sci. 2010; 37: 831-836

Patients in a persistent vegetative state (PVS) are awake but are apparently unaware of themselves or their environment. ${ }^{1}$ The diagnosis of PVS has been made more difficult by recognition of the minimally conscious state as a transitional phase in the partial recovery of self-awareness or environmental awareness as a patient emerges from PVS, leading to a relative high proportion of diagnostic errors. ${ }^{2-10}$

Functional neuroimaging has provided new insights for assessing cerebral function in these patients. Compared to controls, positron emission tomography and single photon emission tomography have shown a substantial reduction of global brain cerebral glucose metabolism and perfusion in PVS. ${ }^{11-15}$

On the other hand, transcranial Doppler ultrasonography (TCD) assesses local blood flow velocity and direction in the proximal portions of large intracranial arteries. Moreover, it is a noninvasive technique, that can be carried out at the bedside, and it is a cost effective method. ${ }^{16-19}$ Nonetheless, few studies have applied TCD to study intracranial circulation in PVS. Shan et al used this technique and concluded that this technique is a

From the Hermanos Ameijeiras Hospital (JPN, CES, MC), Service of Neurology;

Institute of Neurology and Neurosurgery (CM), Department of Clinical Neurophysiology, Havana, Cuba.

Received December 7, 2009. Final Revisions Submitted June 3, 2010. Correspondence to: Calixto Machado, Institute of Neurology and Neurosurgery, Apartado Postal 4268, Ciudad de La Habana, 10400, Cuba. 
Table 1: Patients' clinical and demographic data

\begin{tabular}{lccccc}
\hline Patients & OC & JM & RH & AG & YC \\
\hline Age/Sex & $12 / \mathrm{M}$ & $18 / \mathrm{M}$ & $18 / \mathrm{M}$ & $31 / \mathrm{M}$ & $21 / \mathrm{F}$ \\
Etiology & Near drown & Near drown & Near drown & $\begin{array}{c}\text { Anesthetic } \\
\text { accident }\end{array}$ & $\begin{array}{c}\text { Top basilar } \\
\text { infarct }\end{array}$ \\
Evolution & 6 years & 8 years & 4 years & 6 years & 1 year \\
JFK Scale & 6 & 4 & 3 & 4 & 4 \\
\hline
\end{tabular}

Patient's clinical and demographic features are summarized. M=Male, F=Female, JFK=

valuable tool in distinguishing PVS, locked-in syndrome and brain death patients according to the differences in velocities and patterns of anterior and posterior cerebral arteries. ${ }^{20}$ Shiogai et al evaluated cerebrovascular reserve capacity in relation to cerebral cognitive impairments between PVS and vascular dementia, assessing TCD acetazolamide vasoreactivy. ${ }^{21}$

Hence, taking in to consideration those reports about substantial reduction of global brain cerebral glucose metabolism and perfusion, ${ }^{11-15}$ and vasoreactivity decrement in PVS, ${ }^{21}$ we postulate that TCD should be a useful tool for detecting changes of cerebral circulation in this condition.

\section{Materials And Methods}

The clinical and demographic features of the patients are summarized in Table 1. We evaluated five PVS patients, four men and one woman, aged 12 to 31 years. The cause of brain insult was hypoxic encephalopathy in four cases (three patients experienced near-drowning; one had cardio-respiratory arrest during surgery); the last patient had an embolic cerebral infarct causing a top of the basilar artery syndrome. We also studied 20 normal subjects, ten males and ten females, aged 10 to 35 years old, for setting our TCD normative data.

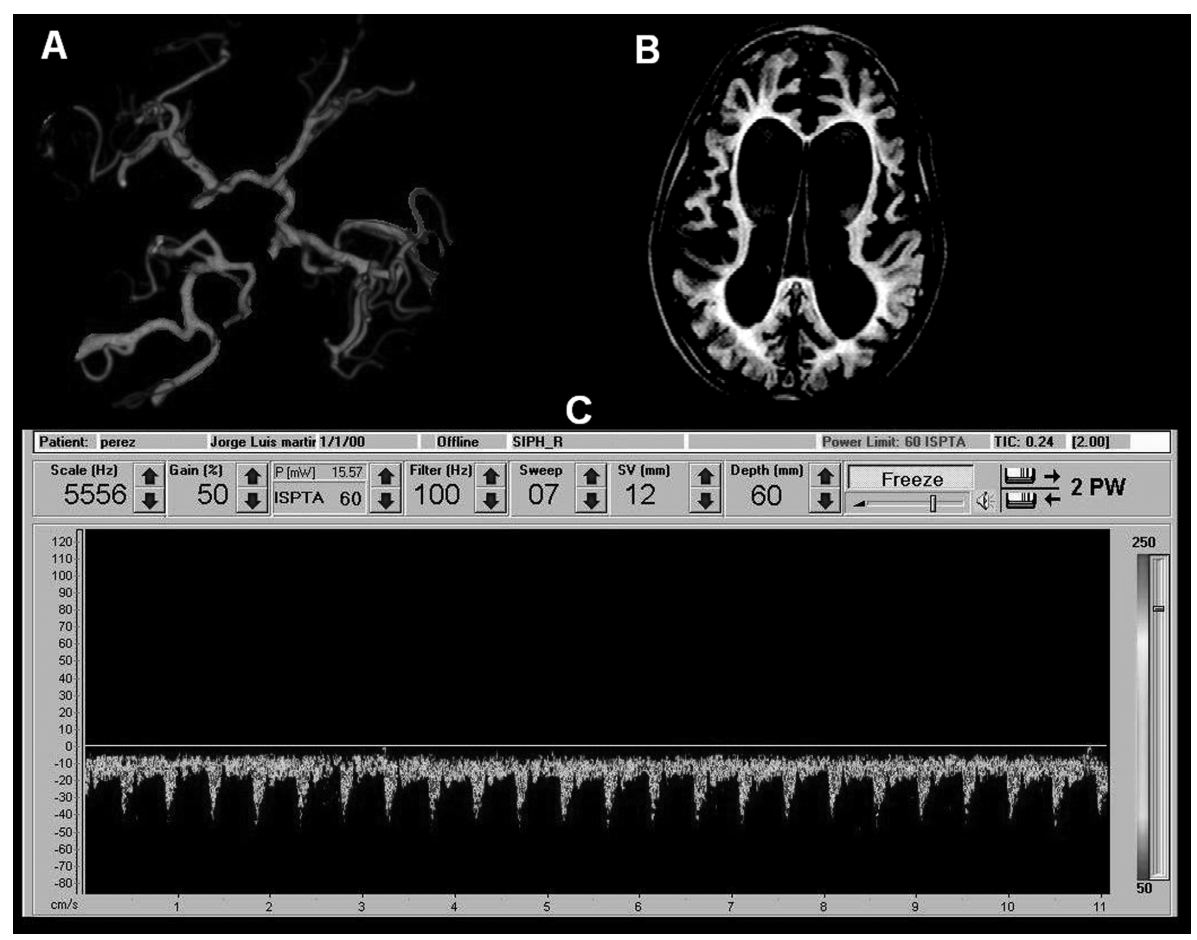

Figure 1: CT angiography, MRI and TCD of patient JM. (A) CT angiography of patient JM demonstrates normal arterial anatomy and preserved intracranial circulation. B) MRI (Flair) shows severe atrophy with ventriculomegaly. C) TCD of right internal carotid artery siphon reveals a decreased diastolic flow. 


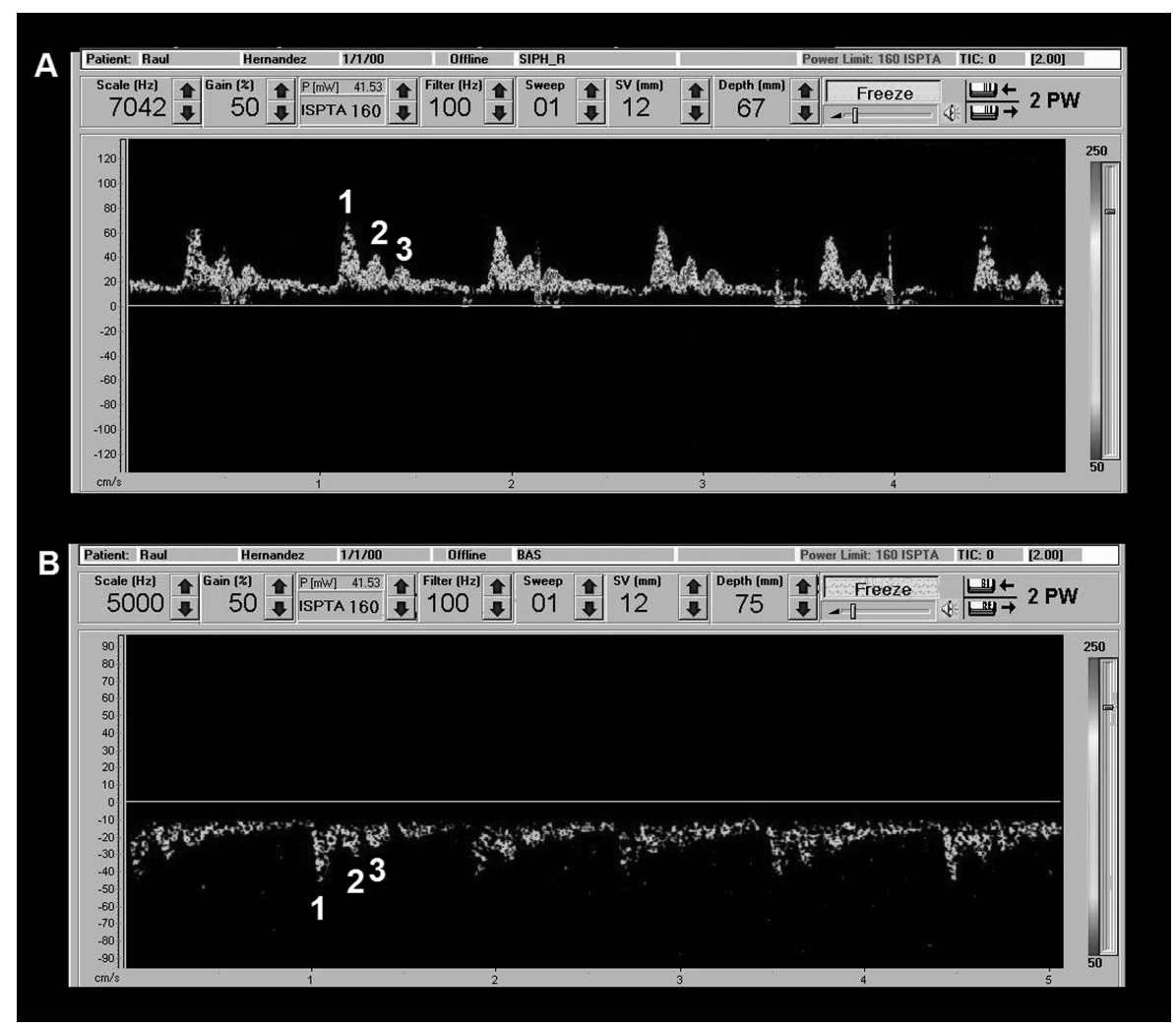

Figure 2: TCD of right internal carotid artery siphon and basilar artery of patient RH.TCD waveforms of right internal carotid artery siphon $(A)$ and basilar artery $(B)$ reveal a decreased diastolic flow with preservation of the first systolic peak (1), Windkessel effect (2), and the diastolic notch (3).

The patients were in PVS for a long time (average: 5 years, range: 1-8 years). They showed no evidence of gestural or verbal communication, no ability to follow commands, and no visual pursuit, or purposeful motor behavior, fulfilling PVS diagnostic criteria.-10 Auditory, visual, motor, oromotor, communication, and arousal processes were assessed in all cases by the JFK scale, ${ }^{22}$ ranging from 3 and 6 points.

Patients were studied by non-contrast computed tomography (CT) and magnetic resonance imaging (MRI). In order to measure the temporal bone thickness, CT window settings were adjusted for bone evaluation (window width was 1000 Hounsfield Units, and window level was 200 Hounsfield Units).

Transcranial doppler studies were performed by two experienced operators. An Embo-Dop, DWL TCD machine, with a 2-MHz pulse-wave Doppler transducer, was used for all studies.

The temporal bone acoustic window was not suitable for intracranial vessel insonation in all patients, possibly due to an augmentation of temporal bone thickness (the skull diploid thickness in the area of the temporal window was above $3.4 \mathrm{~mm}$ in all cases). As an alternative, the internal carotid artery siphon was assessed by orbital insonation between $55-70 \mathrm{~mm}$. For transorbital examination the transducer unit power output was reduced to less than $17 \mathrm{mw} / \mathrm{cm}^{2}$. The extracranial internal carotid was studied with a 2-MHz pulse-continuous Doppler transducer through a submandibular window. For each artery, peak-systolic, end-diastolic velocities, and resistive indices were recorded.

This research was approved by the ethical committees of the Institute of Neurology and Neurosurgery, and Hermanos Ameijeiras Hospital, in Havana, Cuba. The research protocol was explained to patients' relatives who signed an informed consent form.

\section{RESULTS}

In Figure 1, CT angiography of patient JM demonstrates normal arterial anatomy and preserved intracranial circulation, MRI-Flair shows severe white matter and cerebral cortex atrophy with ventriculomegaly, and TCD of the right internal carotid artery siphon reveals decreased diastolic flow. Transcranial doppler of the right internal carotid artery siphon and basilar artery of patient RH reveal a decreased diastolic flow, preserving relative normal TCD waveform, with the presence of the first systolic peak, Windkessel effect, and the diastolic notch. ${ }^{23}$ (Figure 2).

Transcranial doppler results of the right internal carotid artery siphon are shown in Table 2. Peak-systolic, end-diastolic, mean velocities and resistive indexes are presented. Systolic velocity was within a normal range, between 44 and $62 \mathrm{~cm} /$ second in all 
Table 2: Carotid artery siphon TCD results

\begin{tabular}{|c|c|c|c|c|c|c|c|}
\hline & Mean & $\begin{array}{l}\text { PVS } \\
\text { SD }\end{array}$ & Range & Mean & $\begin{array}{l}\text { ntrols } \\
\text { SD }\end{array}$ & Range & $p$ \\
\hline $\begin{array}{l}\text { Systolic } \\
\text { velocity }\end{array}$ & 51.2 & 6.9 & $44-62$ & 59.9 & 17.2 & $33-93$ & 0.303 \\
\hline $\begin{array}{l}\text { End diastolic } \\
\text { velocity }\end{array}$ & 4.8 & 1.3 & $4-7$ & 27.3 & 11.1 & $11-48$ & 0.001 \\
\hline Mean velocity & 19.3 & 2.2 & $16-22$ & 39.4 & 15.1 & $19.3-69$ & 0.012 \\
\hline $\begin{array}{l}\text { Pulsatility } \\
\text { Index }\end{array}$ & 2.4 & 0.24 & $2-2.6$ & 0.88 & 0.29 & $0.53-1.5$ & 0.000 \\
\hline $\begin{array}{l}\text { Resistive } \\
\text { Index }\end{array}$ & 0.88 & 0.04 & $0.8-0.9$ & 0.55 & 0.11 & $0.39-0.75$ & 0.000 \\
\hline
\end{tabular}

TCD results of the right carotid artery siphon comparing patients with normal subjects. Systolic velocity was within a normal range in all patients, while the end diastolic velocity was significantly reduced. Pulsatility Index was significantly increased in all patients, as well as the resistive index. $\mathrm{SD}=$ standard deviation

cases. However, the end diastolic velocity was significantly reduced. The pulsatility index was significantly increased in all patients, with values over 2 points (normal values: $0.5-1.4$ ). The resistive index was 0.9 in four patients and 0.8 in one (normal values: $0.4-0.75)$.

\section{Discussion}

Transcranial doppler of intracranial arteries shows rounded waveforms with low pulsatility index (PI), due to the relative low vascular resistance of intracranial vessels. ${ }^{24-26}$ The first systolic peak is predominantly related to myocardial contractility, and the second one (Windkessel effect) is associated with the distensibility (compliance) of the arterial wall and subsequent volume displacement effect. ${ }^{23}$

The diastolic perfusion pressure drops when intracranial pressure (ICP) increases, and the diastolic TCD wave gradually disappears. As the ICP rises the Windkessel effect disappears and the systolic peak sharpens and narrows, because elasticity of the intracranial vessels becomes dysfunctional (vasoparalysis) and extramural pressure rises because of cerebral swelling. Both of these effects limit expansion of the intracranial arteries when the aortic valve opens in the cardiac cycle..$^{23,27-30}$ When ICP rises to values higher than the diastolic blood pressure, the result is an oscillating flow with systolic spikes, and patterns that characterize cerebral circulatory arrest. ${ }^{16,19,24,31-34}$ Other conditions that increase cerebrovascular resistance, especially small vessel disease, could lower diastolic velocity and increase PI. ${ }^{35-37}$

In spite of the diastolic flow decay, the TCD waveforms in our patients retained relatively normal configuration, showing both systolic peaks, and the dicrotic notch. Neuroimaging of our patients gave no evidence of increased vascular resistance but decreased metabolic demand might have roused high vascular resistance to cerebral blood flow $(\mathrm{CBF})$ in intracranial arteries.

Neuroimaging of our patients gave no evidence of an increased vascular resistance due to an ICP rise. Hence, the TCD findings in our cases, characterized by a diastolic velocity decay and PI augmentation, were not related to an increased intracranial vascular resistance.

Cerebral blood flow and cerebral metabolic rate are normally coupled in that increased metabolic demand leads to an increase in CBF. ${ }^{38-40}$ Studies conducted in normal humans have demonstrated a quite consistent coupling between brain metabolism and CBF. Glucose consumption and oxygen brain uptake seem to be tightly coupled to neurotransmitter recycling and restoration of neuronal membrane potentials through conversion of glucose to lactate in astrocytes, and shuttling of lactate to neurons for oxidation. ${ }^{39,41}$

On the other hand, several authors have reported that the overall cortical metabolism of patients in PVS is $40-50 \%$ of normal ${ }^{11,14,42-45}$ Hence, we conclude that TCD diastolic velocity decrement and PI augmentation in our cases might be related to uncoupling of $\mathrm{CBF}$ and cerebral metabolic rate, arising from reduced cerebral glucose consumption and oxygen uptake, after extensive brain injury.

A limitation of the present study is that intracranial arteries were not assessed through a temporal window. An unexpected TCD finding was an absence of the temporal insonation window in our five patients. The absence of TCD temporal window has been related to advancing age, female gender, and temporal bone thickness. ${ }^{46}$ A cutoff point of temporal bone thickness in the area of the temporal window of $2.7 \mathrm{~mm}$ has been proposed as limit for a TCD successful insonation. ${ }^{47}$ Our five cases showed temporal bone thickness above this value. It might be due to the nutritional shortage or cerebral metabolic disorder. ${ }^{48-50}$ Further research is needed on this subject.

Another drawback of this paper is the small sample of patients, but due to the importance of our findings, and the relative rarity of patients in this condition, we decided to reports these results. 


\section{Conclusion}

In conclusion, TCD may be helpful in assessing the intracranial circulation in PVS at bedside, at patient's home or at institutions. Hence, this technique may be useful in follow-up studies during neurorehabilitation programs, providing an indirect index of cerebral metabolic rate and perfusion.

\section{REFERENCES}

1. Giacino J, Whyte J. The vegetative and minimally conscious states: current knowledge and remaining questions. J Head Trauma Rehabil. 2005; 20:30-50.

2. Jennett B, Plum F. Persistent vegetative state after brain damage. A syndrome in search of a name. Lancet. 1972; 1:734-7.

3. Vanhaudenhuyse A, Noirhomme Q, Tshibanda LJ, Bruno MA, Boveroux P, Schnakers C, et al. Default network connectivity reflects the level of consciousness in non-communicative braindamaged patients. Brain. 2010; 133(Pt 1):161-71.

4. Giacino JT, Malone R. The vegetative and minimally conscious States. Handb Clin Neurol. 2008; 90:99-111.

5. Owen AM, Coleman MR. Detecting awareness in the vegetative state. Ann N Y Acad Sci. 2008; 1129:130-8.

6. Tshibanda L, Vanhaudenhuyse A, Boly M, Soddu A, Bruno MA, Moonen G, et al. Neuroimaging after coma. Neuroradiology. 2010; 52(1):15-24.

7. Monti MM, Coleman MR, Owen AM. Neuroimaging and the vegetative state resolving the behavioral assessment dilemma? Ann N Y Acad Sci. 2009; 1157:81-9.

8. Machado C, Korein J, Aubert E, Bosch J, Alvarez MA, Rodríguez $\mathrm{R}$, et al. Recognizing a mother's voice in the persistent vegetative state. Clin EEG Neurosci. 2007; 38(3):124-6..

9. Machado C. Brain death. A reappraisal. New York: Springer; 2007: p. 1-223.

10. Machado C. Persistent vegetative and minimally conscious states. Rev Neurosci. 2009; 20(3-4):203-20.

11. Laureys S, Owen AM, Schiff ND. Brain function in coma, vegetative state, and related disorders. Lancet Neurol. 2004; 3 : 537-46.

12. Boly M, Faymonville ME, Schnakers C, Peigneux P, Lambermont $\mathrm{B}$, Phillips $\mathrm{C}$, et al. Perception of pain in the minimally conscious state with PET activation: an observational study. Lancet Neurol. 2008; 7(11):1013-20.

13. Nakayama N, Okumura A, Shinoda J, Nakashima T, Iwama T. Relationship between regional cerebral metabolism and consciousness disturbance in traumatic diffuse brain injury without large focal lesions: an FDG-PET study with statistical parametric mapping analysis. J Neurol Neurosurg Psychiatry. 2006; 77(7):856-62.

14. Owen AM, Coleman MR, Menon DK, Johnsrude IS, Rodd JM, Davis $\mathrm{MH}$, et al. Residual auditory function in persistent vegetative state: a combined PET and fMRI study. Neuropsychol Rehabil. 2005; 15:290-306.

15. Beuthien-Baumann B, Holthoff VA, Rudolf J. Functional imaging of vegetative state applying single photon emission tomography and positron emission tomography. Neuropsychol Rehabil. 2005; $15: 276-82$.

16. Friedlich D, Agner C, Boulos AS, Mesfin F, Feustel P, Bernardini GL, et al. Retrospective analysis of parenteral magnesium sulfate administration in decreased incidence of clinical and neuroradiological cerebral vasospasm: a single center experience. Neurol Res. 2009; 31(6):621-5.

17. White H, Venkatesh B. Applications of transcranial Doppler in the ICU: a review. Intensive Care Med. 2006; 32(7):981-94.

18. Rasulo EA, De Peri E, Lavinio A. Transcranial Doppler ultrasonography in intensive care. Eur J Anaesthesiol Suppl. 2008; 42:167-73

19. Conti A, Iacopino DG, Spada A, Cardali SM, Giusa M, La Torre D, et al. Transcranial Doppler ultrasonography in the assessment of cerebral circulation arrest: improving sensitivity by transcervical and transorbital carotid insonation and serial examinations. Neurocrit Care. 2009; 10:326-35.
20. Shan G, Yining H, Xia H, Yicheng Z, Bo W, Shunwei L. Transcranial Doppler characteristics in persistent vegetative status, locked-in syndrome and brain death. Chin Med Sci J. $1999 ; 14: 211-14$

21. Shiogai T, Koshimura M, Uebo C, Makino M, Mizuno T, Nakajima $\mathrm{K}$. Acetazolamide vasoreactivity in persistent vegetative state and vascular dementia evaluated by transcranial harmonic perfusion imaging and Doppler sonography. Acta Neurochir Suppl. 2003; 87:63-9.

22. Giacino JT, Kalmar K, Whyte J. The JFK Coma Recovery ScaleRevised: measurement characteristics and diagnostic utility. Arch Phys Med Rehabil. 2004; 85:2020-9.

23. Aggarwal S, Brooks DM, Kang Y, Linden PK, Patzer JF 2nd. Noninvasive monitoring of cerebral perfusion pressure in patients with acute liver failure using transcranial doppler ultrasonography. Liver Transpl. 2008; 14:1048-57.

24. Perez-Nellar J, Scherle C, Machado C. TCD systolic spikes in a malignant MCA infarct. Neurocrit Care. 2009; 11:94-6.

25. Miao J, Benkeser PJ, Nichols FT. A computer-based statistical pattern recognition for Doppler spectral waveforms of intracranial blood flow. Comput Biol Med. 1996; 26:53-63.

26. Jorgensen LG. Transcranial Doppler ultrasound for cerebral perfusion. Acta Physiol Scand Suppl. 1995; 625:1-44.

27. Brinck HP, Gran L, Larsen JL. [Delay of retinal fluorescence as a death criterion]. Can Anaesth Soc J. 1979; 26:309-12.

28. Larsen FS, Pott F, Hansen BA, Ejlersen E, Knudsen GM, Clemmesen JD, et al. Transcranial Doppler sonography may predict brain death in patients with fulminant hepatic failure. Transplant Proc. 1995; 27:3510-11.

29. Larsen FS, Strauss G, Knudsen GM, Herzog TM, Hansen BA, Secher NH. Cerebral perfusion, cardiac output, and arterial pressure in patients with fulminant hepatic failure. Crit Care Med. 2000; 28:996-1000.

30. Strauss GI, Høgh P, Møller K, Knudsen GM, Hansen BA, Larsen FS. Regional cerebral blood flow autoregulation in patients with fulminant hepatic failure. Liver Transpl. 2000; 6:795-800.

31. Hassler W, Steinmetz H, Pirschel J. Transcranial Doppler study of intracranial circulatory arrest. J Neurosurg. 1989; 71:195-201.

32. Martinelli O, Benedetti-Valentini F. Trancranial Doppler: value in clinical practice. Int Angiol. 2009; 28(4):249-53.

33. Gur AY, Kesler A, Shopin L, Bornstein NM. Transcranial Doppler for evaluation of idiopathic intracranial hypertension. Acta Neurol Scand. 2007; 116:239-42.

34. Calleja S, Tembl JI, Segura T; Sociedad Española de Neurosonología. [Recommendations of the use of transcranial Doppler to determine the existence of cerebral circulatory arrest as diagnostic support of brain death]. Neurologia. 2007; 22(7): $441-7$

35. Smith EE, Vijayappa M, Lima F, Delgado P, Wendell L, Rosand J, et al. Impaired visual evoked flow velocity response in cerebral amyloid angiopathy. Neurology. 2008; 71:1424-30.

36. Vokatch N, Grötzsch H, Mermillod B, Burkhard PR, Sztajzel R. Is cerebral autoregulation impaired in Parkinson's disease? A transcranial Doppler study. J Neurol Sci. 2007; 254:49-53.

37. Weber BB, Kerr ME, Wechsler LR, Marion DW. Absence of a diastolic velocity notch does not indicate hyperemia in traumatic brain injured patients without elevated cerebral blood flow velocity. J Neurosurg Anesthesiol. 2002; 14:279-86.

38. Ingvar DH, Lassen NA. Cerebral function, metabolism and blood flow. News and trends from the VIIIth international CBF symposium in Copenhagen, June 1977. Acta Neurol Scand. 1978; 57:262-9.

39. Lassen NA, Ingvar DH. Brain regions involved in voluntary movements as revealed by radioisotopic mapping of CBF or CMR-glucose changes. Rev Neurol (Paris). 1990; 146:620-5.

40. Mintun MA, Lundstrom BN, Snyder AZ, Vlassenko AG, Shulman GL, Raichle ME. Blood flow and oxygen delivery to human brain during functional activity: theoretical modeling and experimental data. Proc Natl Acad Sci U S A. 2001; 98:6859-64.

41. Paulson OB, Hasselbalch SG, Rostrup E, Knudsen GM, Pelligrino D. Cerebral blood flow response to functional activation. J Cereb Blood Flow Metab. 2010; 30(1):2-14. 
42. Owen AM, Coleman MR. Using neuroimaging to detect awareness in disorders of consciousness. Funct Neurol. 2008; 23:189-94.

43. Owen AM, Coleman MR. Functional neuroimaging of the vegetative state. Nat Rev Neurosci. 2008; 9:235-43.

44. Coleman MR, Davis MH, Rodd JM, Robson T, Ali A, Owen AM, et al. Towards the routine use of brain imaging to aid the clinical diagnosis of disorders of consciousness. Brain. 2009; 132: 2541-52.

45. Kassubek J, Juengling FD, Els T, Spreer J, Herpers M, Krause T, et al. Activation of a residual cortical network during painful stimulation in long-term postanoxic vegetative state: a $15 \mathrm{O}-\mathrm{H} 2 \mathrm{O}$ PET study. J Neurol Sci. 2003; 212:85-91.

46. Conti A, Iacopino DG, Spada A, Cardali SM, Giusa M, La Torre D, et al. Transcranial Doppler ultrasonography in the assessment of cerebral circulation arrest: improving sensitivity by trancervical and transorbital carotid insonation and serial examinations. Neurocrit Care. 2009; 10:326-35.
47. Kwon JH, Kim JS, Kang DW, Bae KS, Kwon SU. The thickness and texture of temporal bone in brain CT predict acoustic window failure of transcranial Doppler. J Neuroimaging. 2006; $16: 347-52$

48. Kinney HC, Samuels MA. Neuropathology of the persistent vegetative state. A review. J Neuropathol Exp Neurol. 1994; 53:548-58.

49. Adams JH, Graham DI, Jennett B. The neuropathology of the vegetative state after an acute brain insult. Brain. 2000; 123(Pt 7):1327-38

50. Graham DI, Maxwell WL, Adams JH, Jennett B. Novel aspects of the neuropathology of the vegetative state after blunt head injury. Prog Brain Res. 2005; 150:445-55. 